\title{
Drosophila Helical factor is an inducible protein acting as an immune-regulated cytokine in S2 cells
}

\author{
Davide Malagoli ${ }^{a}$, Alice Accorsi ${ }^{a}$, Sandro Sacchi ${ }^{b}, V^{2}$ alentina Basile ${ }^{a}$, Mauro Mandrioli ${ }^{a}$, \\ Marcello Pinti ${ }^{\mathrm{c}}$, Darrell Conklin ${ }^{\text {d,e }}$, Enzo Ottaviani ${ }^{\mathrm{a}, *}$ \\ ${ }^{a}$ Department of Biology, University of Modena and Reggio Emilia, Modena, Italy \\ ${ }^{\mathrm{b}}$ Department of Medicine, Endocrinology, Metabolism and Geriatrics, University of Modena and Reggio Emilia, Modena, Italy \\ ${ }^{\mathrm{c}}$ Department of Biomedical Sciences, University of Modena and Reggio Emilia, Modena, Italy \\ ${ }^{\mathrm{d}}$ Department of Computer Science and Artificial Intelligence, University of the Basque Country UPV/EHU, San Sebastián, Spain \\ e IKERBASQUE, Basque Foundation for Science, Bilbao, Spain
}

\section{A R T I C L E I N F O}

\section{Article history:}

Received 23 May 2011

Received in revised form 3 February 2012

Accepted 4 February 2012

Available online 2 March 2012

\section{Keywords:}

Cytokine

Immunity

Insect

Immune signaling

\begin{abstract}
A B S T R A C T
The innate immunity of Drosophila melanogaster is based on cellular and humoral components. Drosophila Helical factor (Hf), is a molecule previously discovered using an in silico approach and whose expression is controlled by the immune deficiency (Imd) pathway. Here we present evidence demonstrating that Hf is an inducible protein constitutively produced by the $\mathrm{S} 2$ hemocyte-derived cell line. $\mathrm{Hf}$ expression is stimulated by bacterial extracts that specifically trigger the Imd pathway. In absence of any bacterial challenge, the recombinant form of $\mathrm{Hf}$ can influence the expression of the antimicrobial peptides (AMPs) defensin but not drosomycin. These data suggest that in vitro $\mathrm{Hf}$ is an inducible and immune-regulated factor, with functions comparable to those of secreted vertebrate cytokines.
\end{abstract}

(c) 2012 Elsevier Ltd. All rights reserved.

\section{Introduction}

As in mammals, insect innate immunity relies on cellular and humoral components [1,2]. These two elements are interconnected, and the latter, in particular, has been well characterized in insects starting from studies on the larval fat body of the fruit fly Drosophila melanogaster [3]. Among humoral factors, the antimicrobial peptides (AMPs) are the molecules whose structures and functions have been elucidated [4], whereas Drosophila cytokines are less characterized. In mammals, cytokines are chemical mediators involved in immune, neuroendocrine and developmental functions. In invertebrates other than $D$. melanogaster, cytokines have also been retrieved [5-12]. Drosophila and the majority of other invertebrate cytokines display no relevant similarity of primary sequences with mammalian counterparts, and the term cytokine itself has been attributed on a functional criterion, based on an involvement in immunity and development.

Abbreviations: AMP, antimicrobial peptide; Hf, Drosophila Helical factor; Imd, immune deficiency; S2, Schneider's Line 2.

* Corresponding author. Address: Department of Biology, University of Modena and Reggio Emilia, Via Campi 213/D, 41125 Modena, Italy. Tel.: +39 059 2055536; fax: +390592055548.

E-mail address: enzo.ottaviani@unimore.it (E. Ottaviani).
The Drosophila cytokine Spätzle is the activator of the Toll pathway, a cascade activated mainly by Gram positive bacteria and fungi [13]. The protein Spätzle acts through the binding of the receptor Toll and one of its typical effects is the induction of the AMP gene drosomycin [14]. Recently it has also been demonstrated that the secretion of Spätzle by the hemocytes is fundamental to set up a proper systemic response against septic injury or oral infection [15] and also molecular details underpinning Spätzle processing before its interactions with Toll have been provided [16].

A second cytokine observed in D. melanogaster, Unpaired (Upd)3 , is secreted by hemocytes after septic injury and activates the JAK-STAT pathway in the fat body. However, the control of Upd-3 secretion has so far not been fully clarified [17], whereas its expression seems not to depend from the Imd-related kinase dTAK1 [18]. Finally, we have isolated the gene of a putative helical cytokine, Drosophila Helical factor [19], now indexed as Helical factor (Dmel/Hf) in Flybase. Hf expression in the S2 hemocytes is dependent on the Imd pathway [18], the signaling pathway controlling the response to Gram negative bacteria [20].

In the present study, our aim has been to obtain more direct evidence of the role of $\mathrm{Hf}$ as a cytokine, providing further information on the action it may play on the immune function of cultured hemocytes. Our results indicate that $\mathrm{Hf}$ expression is significantly increased after exposure to Escherichia coli-purified peptidoglycan 
[PGN $(-)$ ], while the peptide is no longer visible in the cytoplasm of S2 cells after immune stimulus with heat-inactivated Gram negative bacteria. The direct administration of the recombinant form of $\mathrm{Hf}$, rHf, increases the expression of $\mathrm{Hf}$ and the AMP defensin but not drosomycin in S2 cells. These findings indicate that Hf behaves in vitro analogously to vertebrate secreted helical cytokines.

\section{Materials and methods}

\subsection{Synthesis of the recombinant $\mathrm{Hf}(\mathrm{rHf})$ and the polyclonal antibody anti-rHf}

The cDNA (GenBank Accession No. NM_176064.2) encoding for the full-length form of the protein Hf (Dmel/CG10658) [19] was amplified (rHf_F 5'-GGA TCC GAT GGC GAG ATC AG-3'; rHf_R 5'CTC GAG TTA AGC CTT CGT CC-3', annealing temperature $61^{\circ} \mathrm{C}$, annealing time $45 \mathrm{~s}$, elongation $72{ }^{\circ} \mathrm{C}$ for $45 \mathrm{~s}$ ), initially cloned into the "pGEM T-easy cloning kit" following the instructions of the manufacturer (Promega, Madison, WI, USA) and entirely sequenced on both strands. The obtained $\mathrm{Hf}$ was then cloned in frame into the pET- 32b (+) vector (Novagen, Darmstadt, Germany), containing thioredoxin-, protS- and His-tags. Thioredoxin- and protStags were eliminated by cutting with NdeI and the cut efficiency was analyzed either with DNA electrophoresis in agarose gel and through SDS-PAGE followed by Western blot using an anti-thioredoxin polyclonal antibody (pAb) $(1: 50,000)$ kindly provided by Dr. Carol Imbriano (University of Modena and Reggio Emilia, Modena, Italy). Production and elution of rHf was performed in BL21 (LysS) bacterial cells as already described in detail by Bolognese et al. [21], utilizing a concentration of $1 \mathrm{mM}$ IPTG for induction and $5 \mathrm{mM}$ imidazole for elution. After the elution, dialyzed rHf was run in $12 \%$ SDS-PAGE, bands were cut out from the gel, immersed in $1 \times$ phosphate-buffered saline (PBS) $(137 \mathrm{mM} \mathrm{NaCl}, 2.7 \mathrm{mM} \mathrm{KCl}$, $\left.10 \mathrm{mM} \mathrm{Na}_{2} \mathrm{HPO}_{4}, 10 \mathrm{mM} \mathrm{NaH}_{2} \mathrm{PO}_{4}, \mathrm{pH} 7.3 \pm 0.1\right)$ and then utilized to immunize rabbits (Primm, Milan, Italy). Specificity and sensitivity of the purified anti-rHf pAb were assessed by immunoblot using both rHf and S2 cell lysates as target. For this purpose, total extracts from $2 \times 10^{6}$ cells were prepared by resuspending the cell pellet directly in $150 \mu \mathrm{l}$ of $1 \times$ Laemmli Buffer $(20 \mathrm{mM}$ Tris- $\mathrm{HCl}$ pH 7.5, 1.5 mM EDTA, 20\% Glycerol, 2\% SDS, 5\% $\beta$-mercaptoethanol) added with protease and phosphatase inhibitors. Equivalent amount of total extracts were resolved by $12 \%$ SDS-PAGE, electrotransferred onto nitrocellulose membrane, blocked by incubation in a solution of $5 \%$ non-fat dry milk in $1 \times \mathrm{TBS}(0.15 \mathrm{M} \mathrm{NaCl}$, $50 \mathrm{mM}$ Tris- $\mathrm{HCl} \mathrm{pH} 7.5$ at $25^{\circ} \mathrm{C}, 0.1 \%$ Tween 20 ) and immunoblotted with the following primary antibodies diluted $1: 1000$ in $1 \times$ $\mathrm{TBS} / 1 \mathrm{mg} / \mathrm{ml}$ BSA: anti-rHf pAb; anti-actin (I19) sc-1616 (Santa-Cruz Biotechnology, Santa Cruz, CA, USA). Negative control experiments for immunoblotting were performed substituting the anti-rHf pAb with the pre-immune serum.

\subsection{Cells, cell culture and treatments}

Macrophage-like Drosophila embryonic hemocytes, S2 (also known as SL2) cells, were maintained at $25^{\circ} \mathrm{C}$ in Schneider's Insect medium (Sigma, St. Louis, MO, USA), supplemented with heatinactivated $10 \%$ fetal bovine serum (Sigma). Cell viability was always checked at the beginning and at the end of the experiments, using Trypan blue ( $0.1 \%$, Sigma) dye exclusion method. The percentage of dead cells was similar in both treated and control cells and it was not affected by the experiments. The number of cells positive to Trypan blue staining was between $7 \%$ and $8 \%$ either before or after the experimental procedures (data not shown).

For qPCR experiments focused on elucidating the inducibility of $\mathrm{Hf}, 10^{7} \mathrm{~S} 2$ cells were incubated for 6 or $24 \mathrm{~h}$ in $5 \mathrm{ml}$ of medium added with: $\mathrm{rHf}(1,10,100 \mathrm{pg} / \mathrm{ml}$ and $1,10 \mathrm{ng} / \mathrm{ml})$, or $10 \mu \mathrm{g} / \mathrm{ml}$ PGN(-), i.e., a specific activator of Imd pathway derived from E. coli [22], or the heat-inactivated Gram positive bacteria Staphylococcus aureus $\left(10^{9}\right.$ bacteria/ml), i.e., a potential activator of Toll pathway [23]. Control cells were incubated with culture medium without the addition of recombinant peptide, or PGN(-), or bacteria. The times of incubation were chosen on the basis of the times usually registered to reach a peak response in the typical Imd and Toll readouts [22].

The effects of heat-inactivated E. coli on cytoplasmic Hf were observed through confocal microscopy. In preparation to microscopy analysis, $10^{7} \mathrm{~S} 2$ cells were incubated for 6 or $24 \mathrm{~h}$ in $5 \mathrm{ml}$ of medium containing $10^{9}$ bacteria/ml of heat-inactivated $E$. coli (ATCC 25922 ) or $1 \mathrm{ng} / \mathrm{ml} \mathrm{rHf}$. After treatments, cells were centrifuged and washed in $1 \times$ PBS for three times before starting with the immunocytochemical procedures.

Each experiment was performed at least in triplicate three times.

2.3. $q P C R$ analysis of $\mathrm{Hf}$ expression and inducibility, and evaluation of rHf effects on defensin and drosomycin expression

Control, rHf, PGN(-) and S. aureus-treated S2 cells (6 and $24 \mathrm{~h}$ ) were washed with $1 \times$ PBS and the whole RNA was extracted (SV Total RNA extraction System, Promega) and reverse transcribed to cDNA (GoScript Reverse Transcription System ${ }^{\mathrm{TM}}$, Promega) according to manufacturer's instructions. qPCR reactions were performed using a Maxima ${ }^{\circledR}$ SYBR Green/Fluorescein qPCR Master Mix (Fermentas, Vilnius, Latvia) with the primers, qHf_F 5'-CTC CCG AAG TTG CTC GTC-3' and qHf_R 5'-AAC TGG GTG ACG TTG GAA AC-3' (HPLC-purified), following instruction provided by the manufacturer. The applied thermal profile was: $95^{\circ} \mathrm{C}$ for $10 \mathrm{~min}$ ( $1 \mathrm{cy}-$ cle), $95{ }^{\circ} \mathrm{C}$ for $15 \mathrm{~s}$ and $65^{\circ} \mathrm{C}$ for $30 \mathrm{~s}$ ( 35 cycles). Experiments were performed also with the aim to elucidate if the recombinant peptide, rHf, alone may influence the expression of AMPs, namely defensin and drosomycin. The following primers were used: defensin (F 5'-GCT ATC GCT TTT GCT CTG CT-3' and R 5'-CCA CTT GGA GAG TAG GTC GC- $3^{\prime}$ ), and drosomycin (F $5^{\prime}$-TAC TTG TTC GCC CTC TTC G$3^{\prime}$ and R 5'-GTA TCT TCC GGA CAG GCA GT-3') [18]. For defensin the applied thermal profile was $95^{\circ} \mathrm{C}$ for $10 \mathrm{~min}(1 \mathrm{cycle}), 95^{\circ} \mathrm{C}$ for

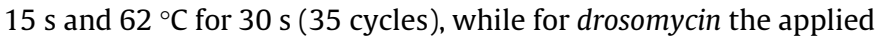
thermal profile was $95{ }^{\circ} \mathrm{C}$ for $10 \mathrm{~min}$ ( $\left.1 \mathrm{cycle}\right), 95^{\circ} \mathrm{C}$ for $15 \mathrm{~s}$ and $60{ }^{\circ} \mathrm{C}$ for $30 \mathrm{~s}$ ( 35 cycles). The housekeeping gene used as reference was ribosomal protein 49 (rp49) (F 5'-AGC AGG AGA TGG CCA CC-3' and R $5^{\prime}$-TCC ACA TCT GCT GGA AGG-3'), and the applied thermal profile was $95{ }^{\circ} \mathrm{C}$ for $10 \mathrm{~min}$ ( $1 \mathrm{cycle}$ ), $95^{\circ} \mathrm{C}$ for $15 \mathrm{~s}$ and $60^{\circ} \mathrm{C}$ for $30 \mathrm{~s}$ (35 cycles). All the reactions were performed in triplicate on a "iQ5" real-time PCR equipment (BIO RAD Lab, Milan, Italy).

\subsection{Immunocytochemical procedure and confocal microscopy}

Treated and control samples of S2 cells were cytocentrifuged onto slides with a "Cytospin II" (Shandon Instrument, UK) running at $800 \mathrm{rpm}$ for $3 \mathrm{~min}$, air-dried for $3 \mathrm{~min}$ at dark, fixed for $5 \mathrm{~min}$ at room temperature (RT) in $4 \%$ paraformaldehyde, washed three times in $1 \times$ PBS for $5 \mathrm{~min}$, incubated for $30 \mathrm{~min}$ in a 1:20 solution of goat normal serum (Vector Lab., Burlingame, CA, USA) and incubated overnight at $4{ }^{\circ} \mathrm{C}$ in $0.2 \mu \mathrm{g} / \mathrm{ml}$ solution of anti-rHf pAb. Slides were then washed repeatedly with $1 \times$ PBS at RT, and cells were permeabilized for $5 \mathrm{~min}$ in a $0.1 \%$ Tween 20 and incubated with 1:1000 FITC-labeled anti-rabbit pAb (Vector Lab.) for $1 \mathrm{~h}$ at RT. After washings, nuclei were counterstained with $10 \mu \mathrm{M}$ Hoecsht 33342 (Ho33342, Sigma) and after four washes in $1 \times$ PBS and a final rinse in bi-distilled water, the slides were mounted in DABCO (Sigma). For each experiment, three slides from both control and treated samples were prepared as described above, but in order 
to exclude any masking of nuclear positivity of immunocytochemical reactions by Ho33342, nuclei were not counterstained. Negative control of immunocytochemical reactions was performed by incubating the cells with pre-immune serum or by pre-adsorbing the antibody with the recombinant peptide, rHf (10 nmol of antigen with $1 \mathrm{ml}$ of undiluted antiserum, incubated overnight at $4{ }^{\circ} \mathrm{C}$ in continue rotation). Negative controls were also performed by omitting the primary antibody in order to exclude any false positive due to the unspecific binding of the secondary antibody. In order to exclude false signal derived from fixation-induced auto-fluorescence, negative controls were also performed by omitting the secondary FITC-labeled anti-rabbit pAb. Confocal microscopy images were acquired with a "Leica DMIRE2" inverted research microscope connected with a TCS SP2-AOBS system (Leica, Germany). Cell integrity was constantly verified by using also transmitted light and phase-contrast imaging. Images were analyzed through the "ImageJ $1.38 \mathrm{x}$ " software (Wayne Rasband, National Institute of Health, USA).

\subsection{Statistical analysis}

Statistical analysis of densitometric values was carried out by ANOVA with $P<0.05$ taken as significant. The statistical analysis of cell viability (data not shown) was performed through Kruskal-Wallis Test. The relative expression of $\mathrm{Hf}$ gene has been calculated as the relative ratio in respect to the first control sample, set arbitrarily to 1, by using the "Delta-Delta Cycle" method [24] and the iQ5 software (BIO RAD Lab.).

\section{Results}

\subsection{Effects of $r H f$, E. coli-derived $P G N(-)$ and heat-inactivated $S$. aureus on the expression of $\mathrm{Hf}$}

qPCR experiments show that rHf triggers $H f$ expression in S2 cells on a time- and concentration-dependent basis. At the concentration of $1 \mathrm{ng} / \mathrm{ml}$, the effects of rHf appear significant only after $24 \mathrm{~h}$, when the expression is always more than 10 times higher than in control. When rHf is used at the $10 \mathrm{ng} / \mathrm{ml}$ concentration, it reveals to be most effective after $6 \mathrm{~h}$ while after $24 \mathrm{~h}$ its effects on S2 cells are not evident (Fig. 1). Similarly to rHf, also PGN(-) can induce a significant increase in $\mathrm{Hf}$ expression. More precisely, $\mathrm{PGN}(-)$ increases $\mathrm{Hf}$ expression up to 15 times in some experiments, even though the average $H f$ expression in $\mathrm{PGN}(-)$-treated cells is approximately 5-6 times higher in comparison with control (Fig. 1). PGN(-) effects on $\mathrm{Hf}$ are similar either after 6 or $24 \mathrm{~h}$. Heat-inactivated $S$. aureus has no effects on the expression of $H f$, neither after 6 nor 24 h incubation (Fig. 1).

\subsection{Effects of immune challenge or $\mathrm{rHf}$ administration on $\mathrm{Hf}$ localization}

Confocal microscopy observations indicate that S2 cells constitutively contain Hf at the cytoplasmic level (Fig. 2A). Nuclei are always negative to the immunocytochemical reactions. After the exposure to heat-inactivated Gram negative bacteria ( $E$. coli) the signal retrieved in the cytoplasm of S2 cells decreases significantly in proportion to the incubation time. After $6 \mathrm{~h}$ incubation with heat-inactivated E. coli, some signal is still detectable in the cytoplasm (Fig. 2B), but after $24 \mathrm{~h}$ of a continued exposure to the Gram negative bacteria, no immunoreactivity can be detected (Fig. 2C). The administration of $1 \mathrm{ng} / \mathrm{ml} \mathrm{rHf}$ to the S2 exerts effects comparable to those described for the bacteria, but with different timings. After $6 \mathrm{~h}$ incubation with $1 \mathrm{ng} / \mathrm{ml}$ of rHf, immunoreactivity for $\mathrm{Hf}$ at the cytoplasmic level is significantly reduced (Fig. 3). Immunoblot experiments confirm the sensitivity of the anti-rHf pAb (Fig. 4) and evidence that rHf, as it has been observed for other proteins [25,26], displays an anomalous electrophoretic mobility, at approximately 30-32 kDa instead of the expected $24.3 \mathrm{kDa}$. Immunoblot experiments can not detect a significant signal either in the cell lysates or in the medium conditioned by control and treated S2 cells (data not shown). This may be imputable to the very low concentration of the factor, given that the signal after immunoblotting is clearly visible only when more than $10 \mathrm{ng}$ of purified rHf are loaded in the gel (Fig. 4).

\subsection{Effects of rHf on the expression of defensin and drosomycin}

qPCR experiments indicate that when directly administered to the cells rHf provokes a time- and concentration-dependent induction of defensin (Fig. 5) whereas it is almost ineffective in modifying the expression of drosomycin (Fig. 6). Concentrations lower than

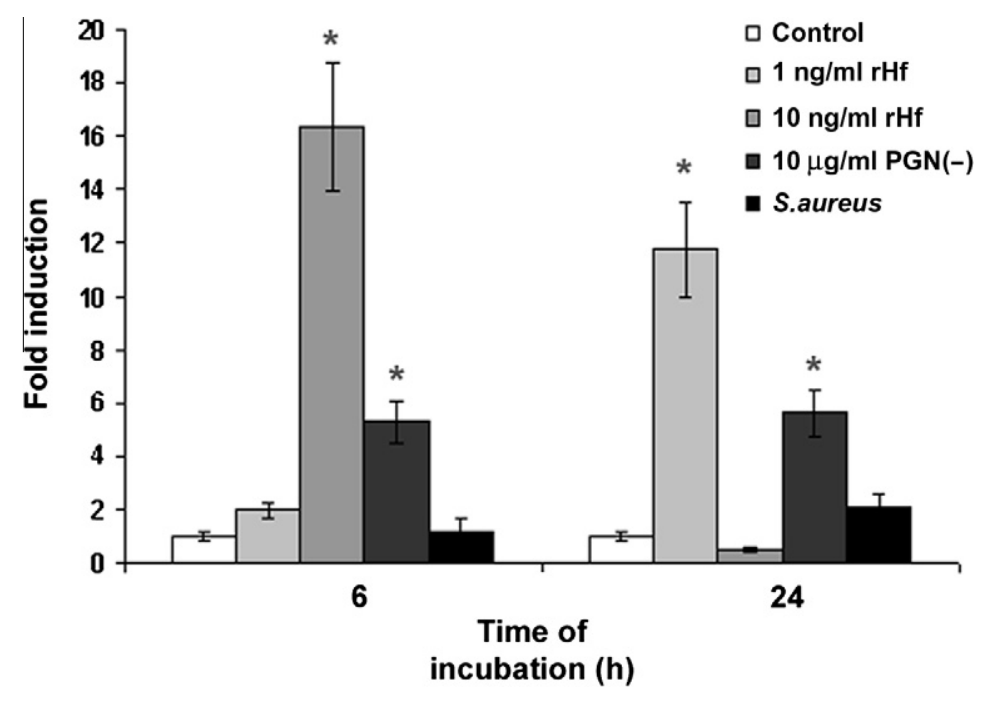

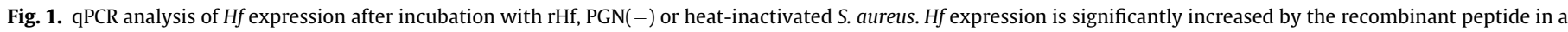

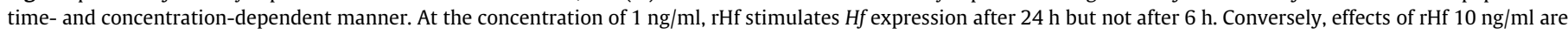

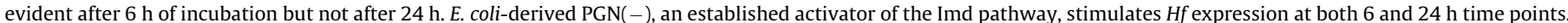

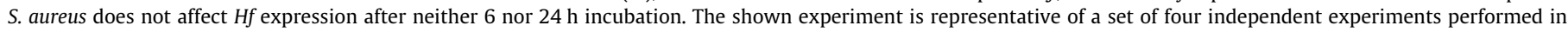
triplicate. ${ }^{*} P<0.05$ vs. Control. 

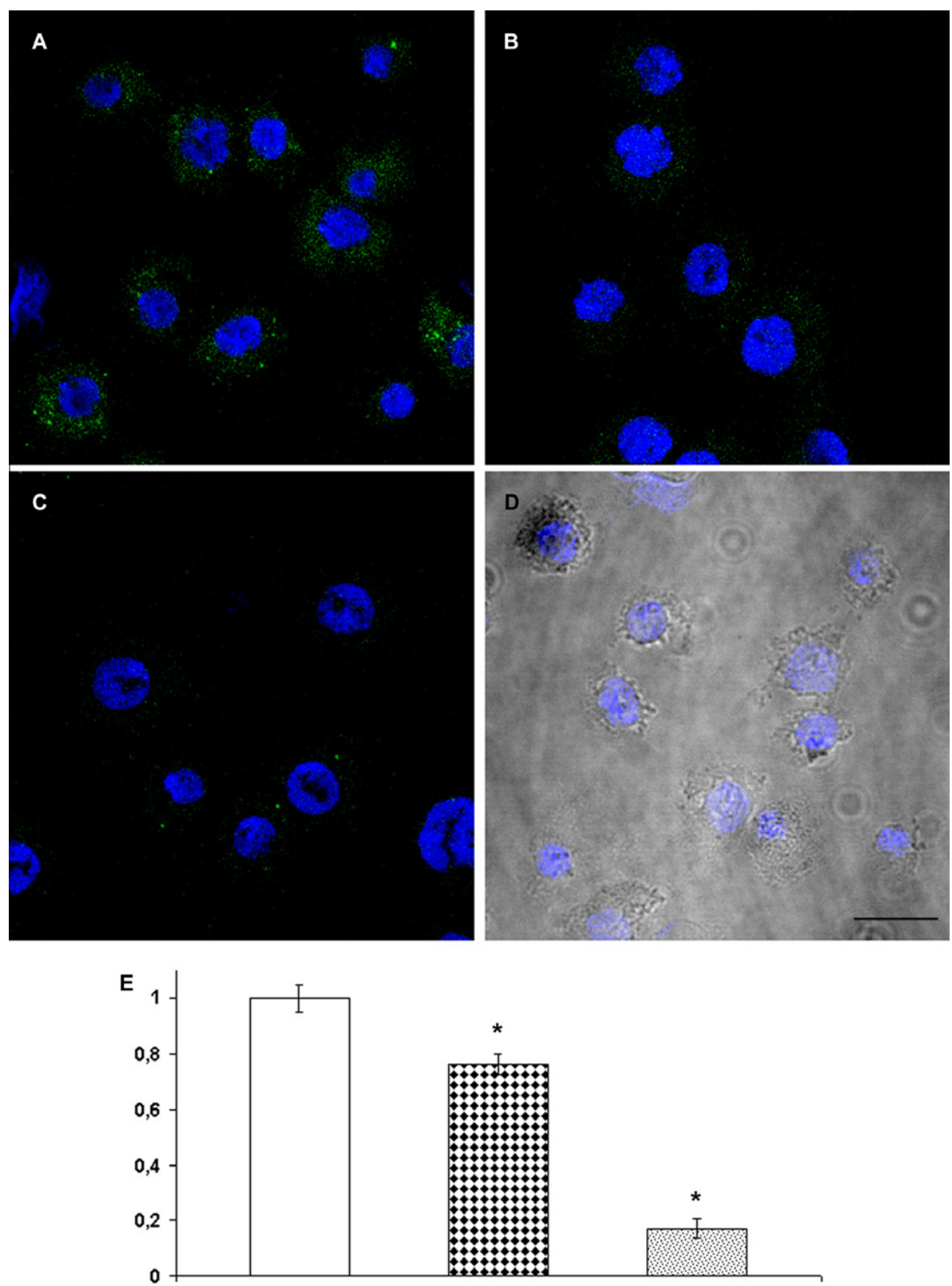

a

b

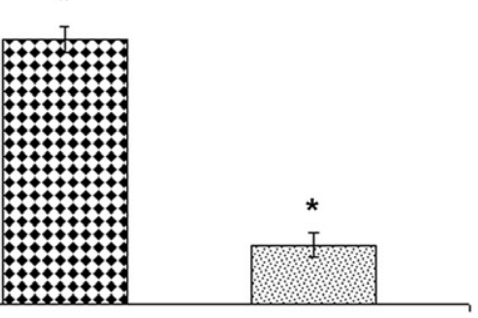

C

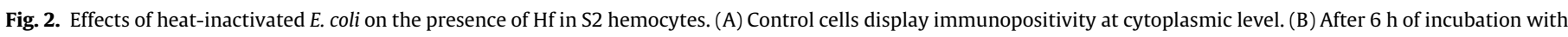

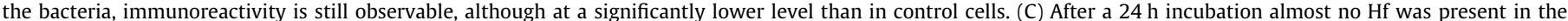

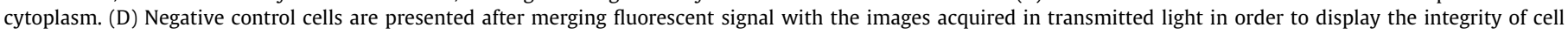

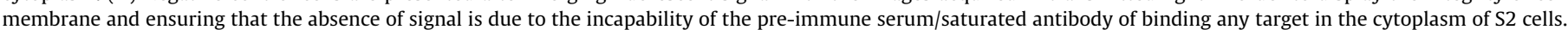

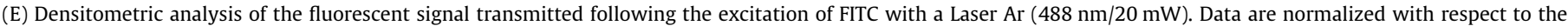
signal registered in control S2 cells (a), and show the difference for the cells incubated with bacteria either for $6 \mathrm{~h}(\mathrm{~b})$ or $24 \mathrm{~h}(\mathrm{c})$. Bar $=10 \mu \mathrm{m}$. ${ }^{*} \mathrm{P}<0.05 \mathrm{vs}$. Control.

$1 \mathrm{ng} / \mathrm{ml}$ (i.e., from 1 to $100 \mathrm{pg} / \mathrm{ml}$ ) do not significantly modify the expression profile of the AMPs (data not shown). When the $1 \mathrm{ng} /$ $\mathrm{ml}$ concentration is used, there is a significant increase in the expression of defensin especially after $24 \mathrm{~h}$ when the expression significantly augmented up to 47 folds (Fig. 5). When S2 cells are incubated with rHf at the highest concentration, i.e., $10 \mathrm{ng} / \mathrm{ml}$, defensin is again significantly increased with respects to controls, and the effects of the recombinant peptide are similar after 6 and $24 \mathrm{~h}$, when defensin is induced approximately 5 folds with respects to control (Fig. 5) drosomycin is almost never affected by the rHf, because only after a $24 \mathrm{~h}$ incubation a very weak induction was observed (Fig. 6). The two immune stimuli applied for estimating the activity of rHf have different effects on S2 cells. PGN(-) stimulates defensin expression either after 6 or $24 \mathrm{~h}$, although at $24 \mathrm{~h}$ the effects are more evident (Fig. 5), but the bacterial extract does not significantly modify the expression profile of drosomycin (Fig. 6). Heat-inactivated $S$. aureus does not affect the expression profile of the two AMPs analogously to what observed for $\mathrm{Hf}$ (Figs. 5 and $6)$.

\section{Discussion}

$\mathrm{Hf}$ is a molecule discovered in D. melanogaster databases by mean of an algorithm specific for helical cytokine searching in molecular databases $[19,27]$. In the present paper, we have observed that $\mathrm{Hf}$, presents the functional characteristics of a cytokine. 

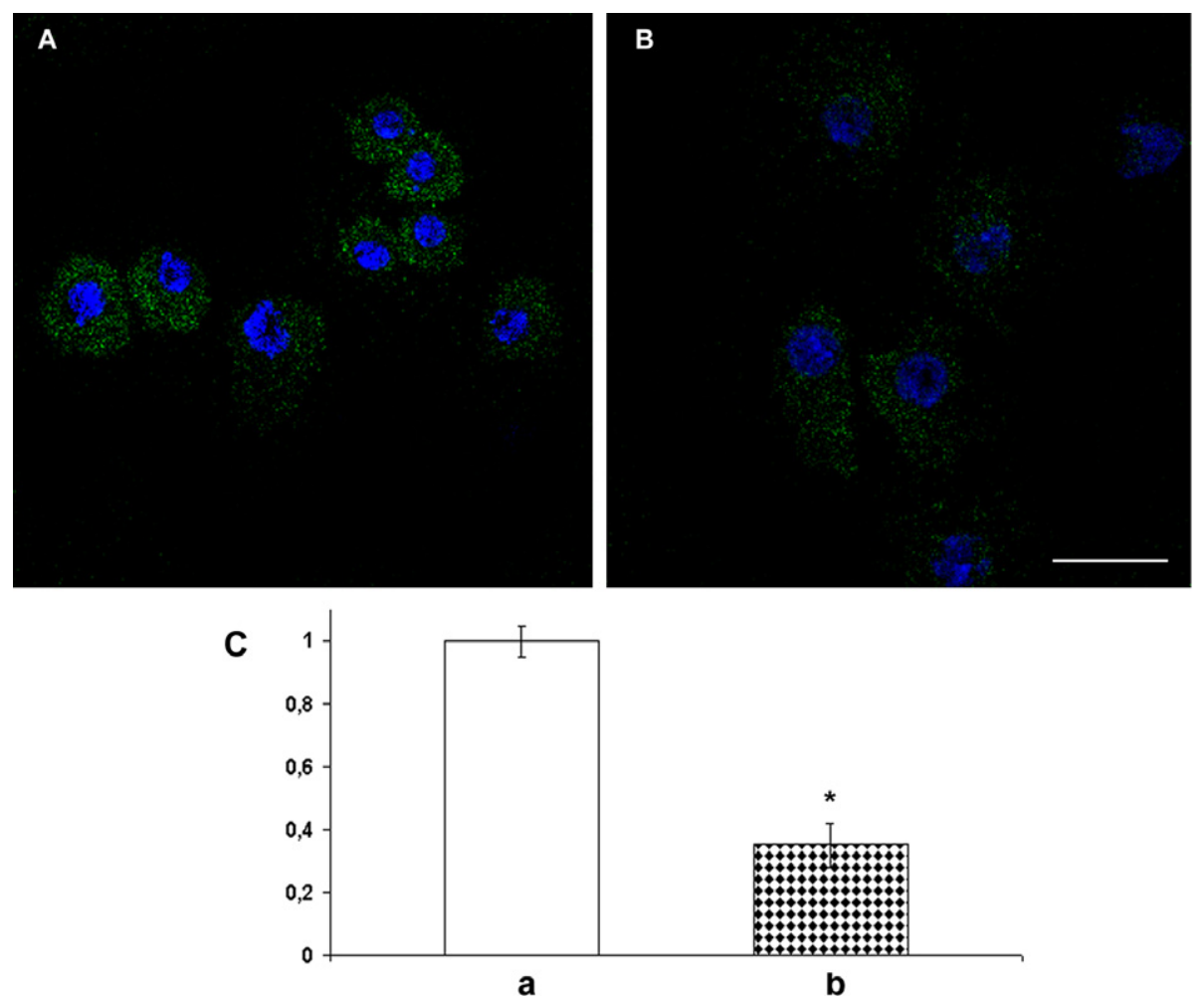

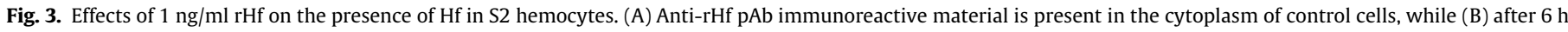

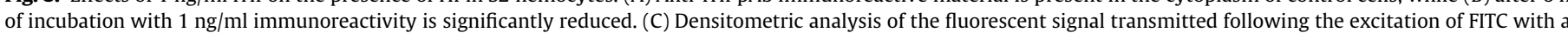

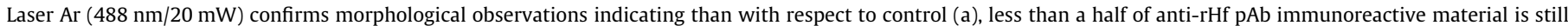

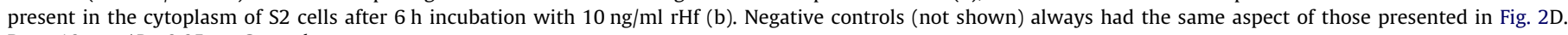
Bar $=10 \mu \mathrm{m} .{ }^{*} P<0.05$ vs. Control.

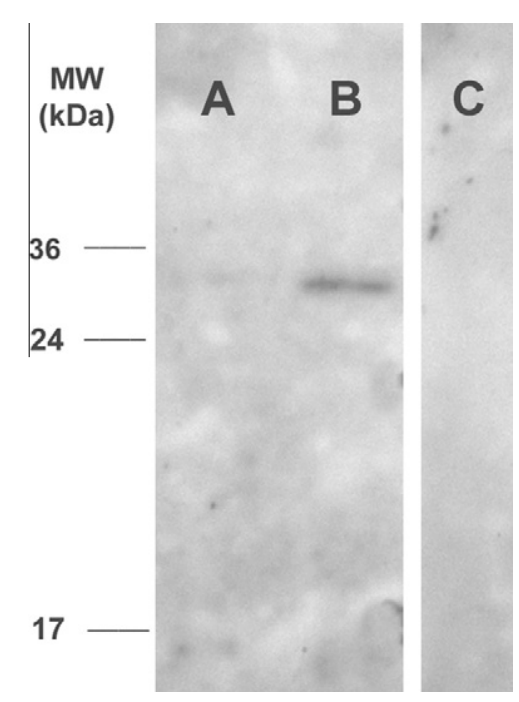

Fig. 4. Immunoblot analysis of the anti-rHf pAb. The antibody is tested against increasing amounts of purified rHf. Up to $10 \mathrm{ng}$ of rHf (lane A) the signal is not clearly detectable, while the band is visible when $20 \mathrm{ng}$ of recombinant peptide are loaded in the gel (lane B). Negative control performed with pre-immune serum is shown in lane $\mathrm{C}$.

We already had indirect evidences concerning the involvement of Hf in Drosophila immunity [18,19], and here we have observed through qPCR that $H f$ is induced after immune stimulation. De Gregorio et al. [28] observed in vivo that after infecting the flies with either a mix of Gram positive and negative bacteria or the entomopathogenic fungus Beauveria bassiana, the CG10658 gene (i.e., $H f$ ) appeared to be suppressed at time points 3 and $6 \mathrm{~h}$, while $\mathrm{Hf}$ was slightly induced $48 \mathrm{~h}$ after the infection. $\mathrm{Hf}$ was not reported among the genes induced in S2 cells after a 60 min treatment with LPS [29]. Here we demonstrate that E. coli-purified PGN(-) stimulated $\mathrm{Hf}$ expression in S2 cells and its effects were similar after either 6 or $24 \mathrm{~h}$ of incubation. These observations obtained with qPCR are in partial contradiction with data we presented before [18], when the PGN(-)-dependent increase of $H f$ expression was observed through semi-quantitative RT-PCR after 18 and $24 \mathrm{~h}$ of incubation but not after $6 \mathrm{~h}$. rHf effects on $\mathrm{Hf}$ expression differ from those of $\mathrm{PGN}(-)$, being time- and concentration-dependent. More precisely, at $1 \mathrm{ng} / \mathrm{ml}$ the recombinant peptide is active mostly after $24 \mathrm{~h}$, whereas at the concentration of $10 \mathrm{ng} / \mathrm{ml}$ the effects are principally evident after $6 \mathrm{~h}$. Previous experiments have demonstrated that the expression of $\mathrm{Hf}$ in $\mathrm{S} 2$ cells is abolished after the silencing of the key component of the Imd signaling, dTAK1 [18]. Present qPCR experiments confirmed the observation since the specific activator of the Imd pathway, PGN(-), is able to induce $H f$ expression while the Gram positive and Toll pathway-activator $S$. aureus does not modify the $\mathrm{Hf}$ expression profile. As a whole, our qPCR experiments have established that $H f$ is an inducible gene in S2 cells, but its induction may vary significantly on the basis of either the type or the duration of the stimulus, suggesting that the typology of the immune challenge and/or the time of incubation are critical for the induction of $H f$.

Beside qPCR data, also confocal microscopy experiments provide further evidence in favor of $\mathrm{Hf}$ as an immune-related signal molecule. After incubating the cells with heat-inactivated E. coli, the immunopositivity versus cytoplasmic Hf declined in a timedependent manner. Since immunoblot experiments failed to evidence $\mathrm{Hf}$ in the medium, at present it is not possible to completely 

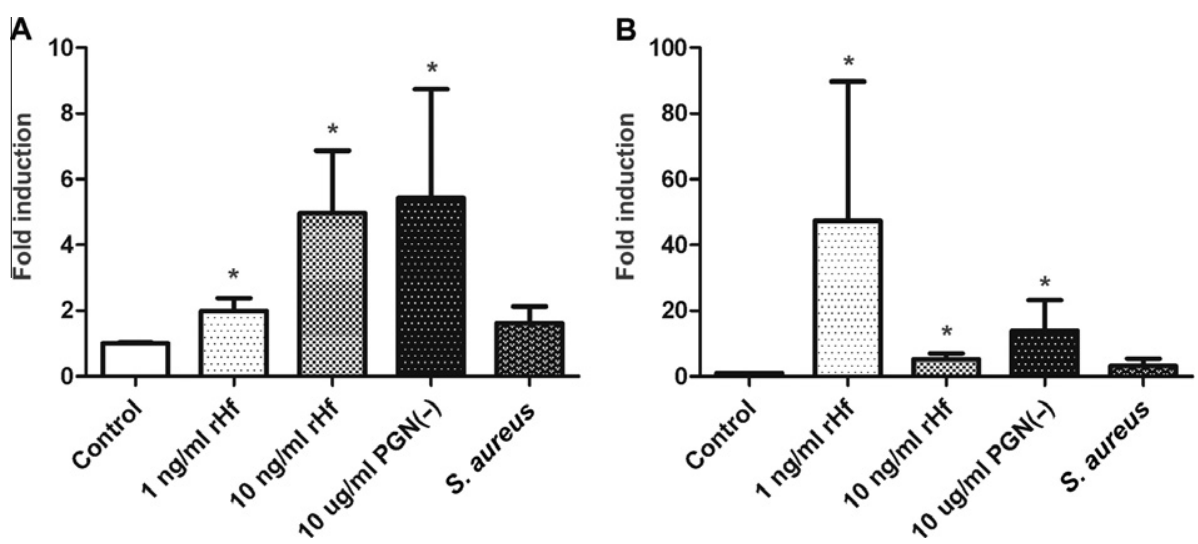

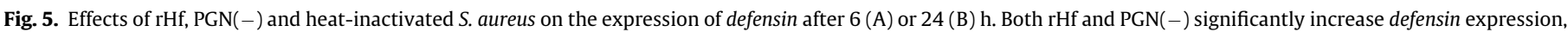

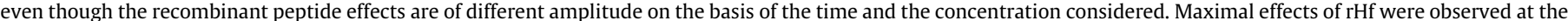
concentration of $1 \mathrm{ng} / \mathrm{ml}$ after $24 \mathrm{~h}$ incubation. Heat-inactivated $S$. aureus never affects the expression of defensin. ${ }^{*} P<0.05$ vs. Control.
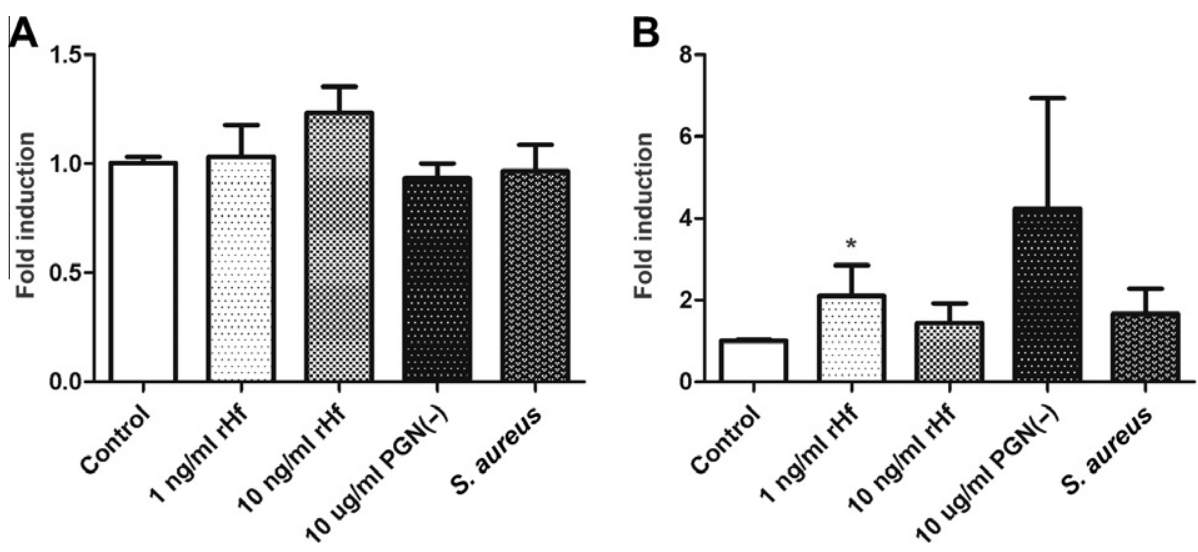

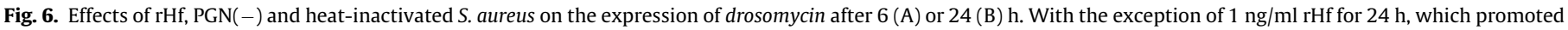
a weak but significant induction, none of the treatments can induce the expression of drosomycin. ${ }^{*} P<0.05$ vs. Control.

rule out the possibility that the factor is degraded as a consequence of the stimulus. However, the specificity of the QT method's predictions $[19,27]$ and the effects exerted by the rHf point towards a probable secretion of the peptide upon an immune challenge. As observed for the $\mathrm{Hf}$ expression, the cytoplasmic presence of $\mathrm{Hf}$ is directly influenced not only by a bacterial stimulation, but also by the recombinant form of the peptide, rHf. This observation is in agreement with data collected in mammals for secreted helical cytokines such as IL-2 and IL-6 [30,31]. Analogously to vertebrate cytokines, also for the Drosophila cytokines Spätzle [15] and Upd3 [17], as well as for other invertebrate cytokines [5,9], it has been demonstrated the secretion by immune-competent cells.

Since our data suggested that besides being an immune-regulated molecule, $\mathrm{Hf}$ is also a secreted factor, we have looked for potential effects of rHf on the AMP synthesis of S2 hemocytes in absence of any immune challenge. As seen for mammalian helical cytokines synthesized by cells of the innate immune system, e.g., macrophages [31], rHf induced a dose- and time-dependent stimulation of the transcription of defensin, and, to a much lesser extent, of drosomycin genes by S2 cells. Notably, the expression profile of $\mathrm{Hf}$ and defensin resulted always very similar in our experiments, as the two genes appeared to be induced by the same stimuli and with a comparative amplitude. Defensin is an AMP typically active against Gram positive bacteria [4]. Drosomycin is mainly effective against fungi and is usually considered as the readout of the Toll signaling pathway activation $[2,22]$, but its expression in ecdysone-treated S2 cells is increased also by E. coli-derived PGN, i.e., a typical activator of the Imd pathway [22]. Here we observed that PGN $(-)$ exerts no induction of drosomycin even after $24 \mathrm{~h}$, confirming the low responsiveness of drosomycin to $\mathrm{PGN}(-)$ in $\mathrm{S} 2$ cells in absence of a pre-treatment with ecdysone [22]. In our experiments, treatments with heat-inactivated $S$. aureus do not significantly affect $H f$ and AMP expression. This is in agreement with recent observations performed in adult flies indicating that $S$. aureus could be able to hamper the humoral immune response in $D$. melanogaster by interfering with the sensing of peptidoglycan [23]. The synergistic cooperation of Toll and Imd pathways has been demonstrated in S2 cells, and it has been proposed that the overlap of the two routes is hinged on the regulating regions of AMP genes and the interactions of the DIF and Relish transcription factors $[22,32]$. Interest in this kind of information also derives from the consideration that Toll and Imd pathways display interesting parallelisms with events triggered in mammals by IL-1 [13], and the TNF-receptor [33], respectively.

The activation of the Imd pathway in the immune response of $D$. melanogaster can be finely and tightly regulated [32-35], suggesting that in the complex immune system of Drosophila all the components cooperate in order to determine an efficacious response $[32,33]$. In this context, data here presented indicate that $\mathrm{Hf}$ is an immune-regulated factor, inducible by a specific Imd-activator, and with functional characteristics similar to those of secreted helical cytokines [36-38]. Hf is dependent in its expression on 
the kinase dTAK1 [18] and it appears to be sufficient for triggering alone a humoral immune reaction as it has been observed for vertebrate cytokines [37-39].

\section{Conflict of interest}

The authors declare no competing financial interests.

\section{Acknowledgements}

Authors wish to thank Dr. C. Imbriano (University of Modena and Reggio Emilia, Modena, Italy) for helpful advises and technical assistance in the cloning of $\mathrm{Hf}$ gene and for the anti-thioredoxin pAb. We are also grateful to Dr. R. Iseppi and Prof. M. Bondi (University of Modena and Reggio Emilia, Modena, Italy) who kindly provided the bacteria. This work was supported by University of Modena and Reggio Emilia (Grant FAR2008 to D.M. and E.O.) and by the Department of Biology of the University of Modena and Reggio Emilia (Grant "Experimental approaches to the study of evolution" to D.M.).

\section{References}

[1] Nappi AJ, Kohler LM, Mastore M. Signaling pathways implicated in the cellular innate immune responses of Drosophila. Inv Surv J 2004;1:5-33.

[2] Nehme NT, Quintin J, Cho JH, Lee J, Lafarge MC, Kocks C, et al. Relative roles of the cellular and humoral responses in the Drosophila host defense against three gram-positive bacterial infections. PLoS One 2011;3(6):e14743.

[3] Lemaitre B, Hoffmann JA. The host defense of Drosophila melanogaster. Annu Rev Immunol 2007;25:697-743.

[4] Bulet P, Stöcklin R. Insect antimicrobial peptides: structures, properties and gene regulation. Protein Pept Lett 2005;12:3-11.

[5] Nakatogawa S, Oda Y, Kamiya M, Kamijima T, Aizawa T, Clark KD, et al. A novel peptide mediates aggregation and migration of hemocytes from an insect. Curr Biol 2009;19:779-85.

[6] Söderhäll I, Kim YA, Jiravanichpaisal P, Lee SY, Söderhäll K. An ancient role for a prokineticin domain in invertebrate hematopoiesis. J Immunol 2005;174:6153-60.

[7] Lin X, Novotny M, Söderhäll K, Söderhäll I. Ancient cytokines, the role of astakines as hematopoietic growth factors. J Biol Chem 2010;285:28577-86.

[8] Schikorski D, Cuvillier-Hot V, Boidin-Wichlacz C, Slomianny C, Salzet M, Tasiemski A. Deciphering the immune function and regulation by a TLR of the cytokine EMAPII in the lesioned central nervous system using a leech model. J Immunol 2009;183:7119-28.

[9] Croq F, Vizioli J, Tuzova M, Tahtouh M, Sautiere PE, Van Camp C, et al. A homologous form of human interleukin 16 is implicated in microglia recruitment following nervous system injury in leech Hirudo medicinalis. Glia 2010;58:1649-62.

[10] De Zoysa M, Jung S, Lee J. First molluscan TNF-alpha homologue of the TNF superfamily in disk abalone: molecular characterization and expression analysis. Fish Shellfish Immunol 2009;26:625-31.

[11] Parrinello N, Vizzini A, Arizza V, Salerno G, Parrinello D, Cammarata M, et al. Enhanced expression of a cloned and sequenced Ciona intestinalis TNFalphalike (CiTNF alpha) gene during the LPS-induced inflammatory response. Cell Tissue Res 2008;334:305-17.

[12] Zhang X, Luan W, Jin S, Xiang J. A novel tumor necrosis factor ligand superfamily member (CsTL) from Ciona savignyi: molecular identification and expression analysis. Dev Comp Immunol 2008;32:1362-73.

[13] Ferrandon D, Imler JL, Hetru C, Hoffmann JA. The Drosophila systemic immune response: sensing and signalling during bacterial and fungal infections. Nat Rev Immunol 2007;7:862-74.

[14] Weber AN, Tauszig-Delamasure S, Hoffmann JA, Lelièvre E, Gascan H, Ray KP, et al. Binding of the Drosophila cytokine Spätzle to Toll is direct and establishes signaling. Nat Immunol 2003;4:794-800.
[15] Shia AK, Glittenberg M, Thompson G, Weber AN, Reichhart JM, Ligoxygakis P. Toll-dependent antimicrobial responses in Drosophila larval fat body require Spätzle secreted by haemocytes. J Cell Sci 2009;122:4505-15.

[16] Arnot CJ, Gay NJ, Gangloff M. Molecular mechanism that induces activation of Spätzle, the ligand for the Drosophila Toll receptor. J Biol Chem 2010;285:19502-9.

[17] Agaisse H, Petersen UM, Boutros M, Mathey-Prevot B, Perrimon N. Signaling role of hemocytes in Drosophila JAK/STAT-dependent response to septic injury. Dev Cell 2003;5:441-50.

[18] Malagoli D, Sacchi S, Ottaviani E. unpaired (upd)-3 expression and other immune-related functions are stimulated by interleukin- 8 in Drosophila melanogaster SL2 cell line. Cytokine 2008;44:269-74.

[19] Malagoli D, Conklin D, Sacchi S, Mandrioli M, Ottaviani E. A putative helical cytokine functioning in innate immune signalling in Drosophila melanogaster. Biochim Biophys Acta 2007;1770:974-8.

[20] Aggarwal K, Silverman N. Positive and negative regulation of the Drosophila immune response. PLoS Pathog 2008;4:e1000120.

[21] Bolognese F, Imbriano C, Caretti C, Mantovani R. Cloning and characterization of the histone-fold proteins YBL1 and YCL1. Nucleic Acids Res 2000;28:3830-8.

[22] Tanji T, Hu X, Weber AN, Ip YT. Toll and IMD pathways synergistically activate an innate immune response in Drosophila melanogaster. Mol Cell Biol 2007;27:4578-88.

[23] Tabuchi Y, Shiratsuchi A, Kurokawa K, Gong JH, Sekimizu K, Lee BL, et al. Inhibitory role for D-alanylation of wall teichoic acid in activation of insect Toll pathway by peptidoglycan of Staphylococcus aureus. J Immunol 2010;185:2424-31.

[24] Schmittgen TD, Livak KJ. Analyzing real-time PCR data by the comparative C(T) method. Nat Protoc 2008;3:1101-8.

[25] Klenova EM, Nicolas RH, Carne AF, Lee RE, Lobanenkov VV, Goodwin GH Molecular weight abnormalities of the CTCF transcription factor: CTCF migrates aberrantly in SDS-PAGE and the size of the expressed protein is affected by the UTRs and sequences within the coding region of the CTCF gene. Nucleic Acids Res 1997;25:466-74.

[26] Rath A, Glibowicka M, Nadeau VG, Chen G, Deber CM. Detergent binding explains anomalous SDS-PAGE migration of membrane proteins. Proc Natl Acad Sci USA 2009;106:1760-5.

[27] Conklin D. Recognition of the helical cytokine fold. J Comput Biol 2004;11:1189-200.

[28] De Gregorio E, Spellman PT, Rubin GM, Lemaitre B. Genome-wide analysis of the Drosophila immune response by using oligonucleotide microarrays. Proc Natl Acad Sci USA 2001;98:12590-5.

[29] Boutros M, Agaisse H, Perrimon N. Sequential activation of signaling pathways during innate immune responses in Drosophila. Dev Cell 2002;3:711-22.

[30] Arzt E, Páez Pereda M, Costas M, Sauer J, Renner U, Holsboer F, Stalla GK. Cytokine expression and molecular mechanisms of their auto/paracrine regulation of anterior pituitary function and growth. Ann NY Acad Sci 1998;840:525-31.

[31] Kolls JK, McCray Jr PB, Chan YR. Cytokine-mediated regulation of antimicrobial proteins. Nat Rev Immunol 2008;8:829-35.

[32] Tanji T, Yun EY, Ip YT. Heterodimers of NF- $\kappa B$ transcription factors DIF and Relish regulate antimicrobial peptide genes in Drosophila. Proc Natl Acad Sci USA 2010;107:14715-20.

[33] Hoffmann JA. The immune response of Drosophila. Nature 2003;426:33-8.

[34] Aggarwal K, Rus F, Vriesema-Magnuson C, Ertürk-Hasdemir D, Paquette N, Silverman N. Rudra interrupts receptor signaling complexes to negatively regulate the IMD pathway. PLoS Pathog 2008;4:e1000120.

[35] Kleino A, Myllymäki H, Kallio J, Vanha-aho LM, Oksanen K, Ulvila J, et al. Pirk is a negative regulator of the Drosophila Imd pathway. J Immunol 2008;180:5413-22.

[36] Mezzani A, Balosso S, Ravizza T. The role of cytokines in the pathophysiology of epilepsy. Brain Behav Immun 2008;22:797-803.

[37] Finamore E, Vitiello M, D'Isanto M, Galdiero E, Falanga A, Kampanaraki A, et al Evidence for IL-6 promoter nuclear activation in U937 cells stimulated with Salmonella enterica serovar Typhimurium porins. Eur Cytokine Netw 2009;20:140-7.

[38] Mayuzumi H, Inagaki-Ohara K, Uyttenhove C, Okamoto Y, Matsuzaki G. Interleukin-17A is required to suppress invasion of Salmonella enterica serovar Typhimurium to enteric mucosa. Immunology 2010;131:377-85.

[39] Pestka S, Krause CD, Sarkar D, Walter MR, Shi Y, Fisher PB. Interleukin-10 and related cytokines and receptors. Annu Rev Immunol 2004;22:929-79. 